\title{
Graphocephala fennahi, eine hübsche kleine Zikade und gleichzeitig ein Rhododendron-Schädling
}

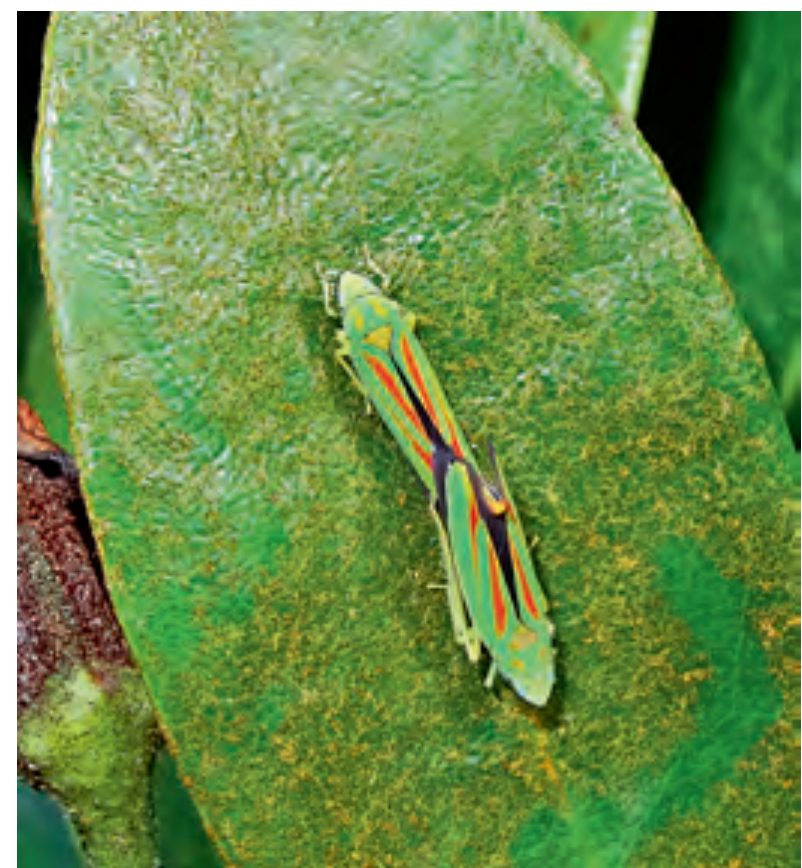

Abb. 1: Rhododendron-Zikaden bei der Paarung. (Foto: B. Jakовus)

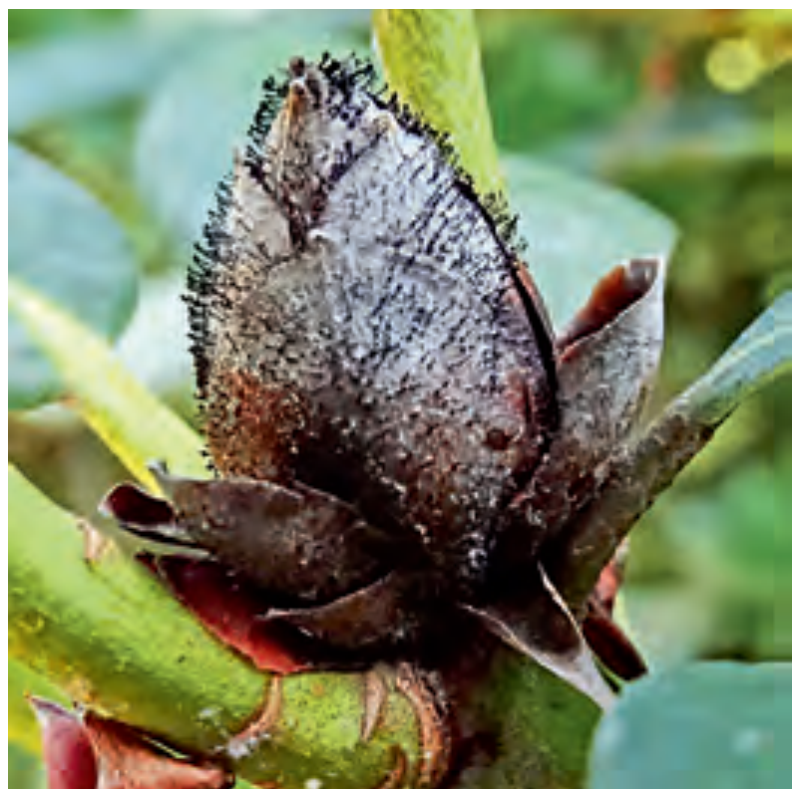

Abb. 2: Knospe von Rhododendron mit Befall durch den Pilz Pycnostysanus azaleae. Die Pilzinfektion wird begünstigt durch Schäden, die Graphocephala fennahi während der Eiablage an den Knospen verursacht. (Foto: В. Јаковиs)

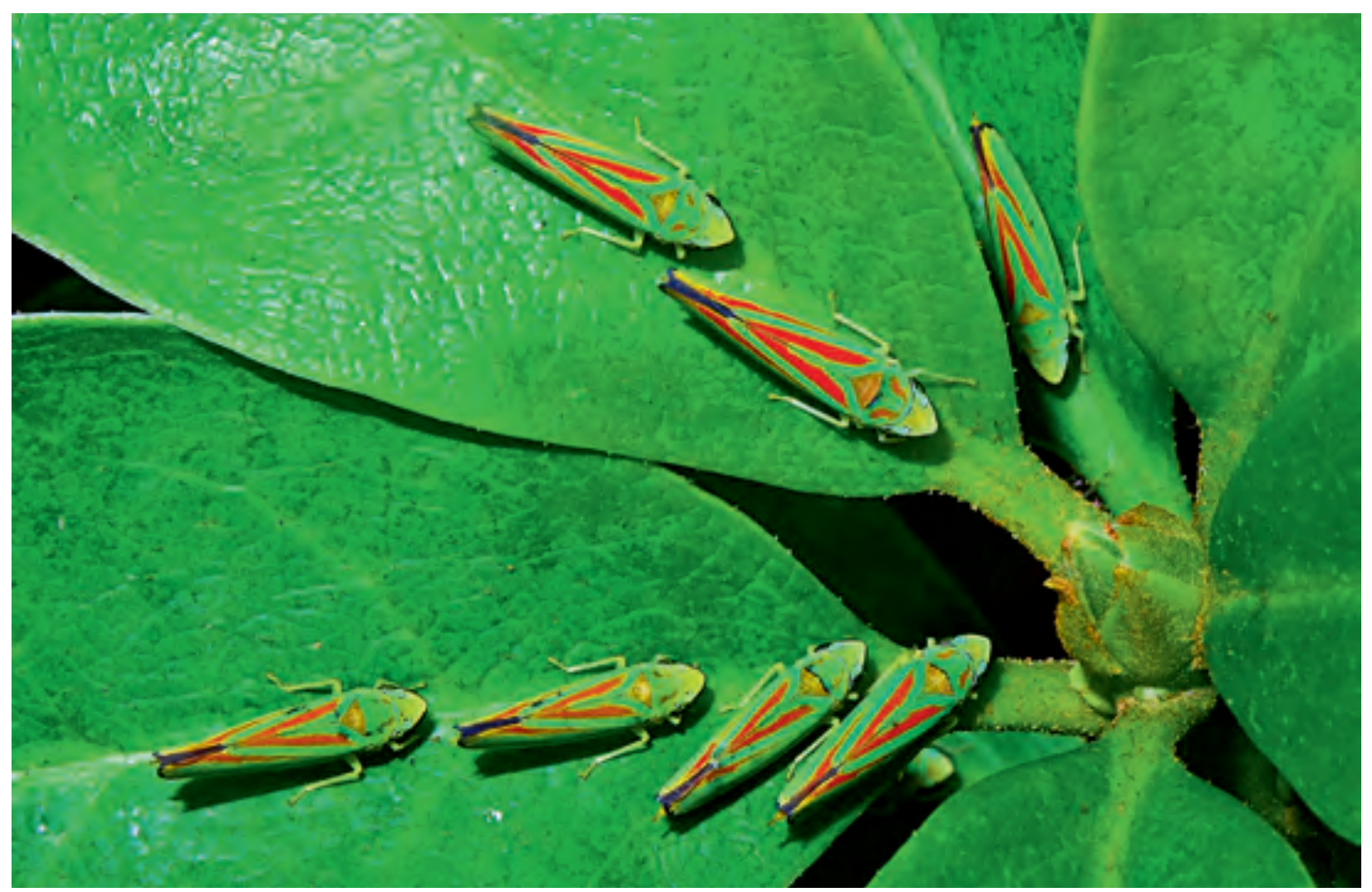

Abb. 3: Im Rhododendrongarten des Palmengartens sowie im Botanischen Garten kann beobachtet werden, dass sich manchmal gleich mehrere Rhododendron-Zikaden auf den Blättern in der Nähe der Knospen aufhalten. (Foto: B. Jakовus) 